\title{
Casa Verde: do plantio à colheita - pedagogia no quintal
}

\author{
Maria do Carmo Ribeiro Abreu * \\ Elizete Maria de Lima $* *$ \\ João Batista de Lima ${ }^{* * *}$
}

\section{Resumo}

Este artigo originou-se do desejo de que os fazeres e os saberes vivenciados na Escola Casa Verde, Aparecida de Goiânia, Goiás/Brasil, ultrapassassem os muros da Escola.. Trabalho baseado em muitos anos de estudos e prática. Planejado na tentativa de romper com a pratica tradicional desde o início. . Nesse fazer, a comunidade escolar e as crianças vivem a experiência de lapidação feito pedra preciosa na direção do sonhado. Este texto tem como objetivo apresentar a Escola, descrever o processo criativo do trabalho pedagógico e justificar a quebra de paradigma na linha de atuação que tece a dinâmica escolar. Contudo, sabemos que as palavras fogem, deixam de alcançar a dimensão do objeto observado. A riqueza do vivido ultrapassa a capacidade do registro. O principal, nessa tarefa, é afirmar que a Casa Verde troca a inércia repetidora por experiências e acontecimentos vinculados à vida que pulsa fora dos muros da escola. Palavras-Chave: Escola Casa Verde, sustentabilidade, pedagogia e criatividade.

\section{Green Home: from planting to harvest - pedagogy in the backyard}

\begin{abstract}
This article originated from the need to record the events and creative experiences having their genesis at the Escola Casa Verde (Greenhouse School) located in Aparecida de Goiania, Goiás, Brazil. Highlighted are the activities and a knowledge base that comprise many thoughtful years of study and experience; in which the premise has been a commitment to innovation and creativity, a process always accompanied by the School's community and its young students. Each day brings novelties and with it revelations as the students evolve, reminding one of the faceting of a gemstone. The Objectives: To present the school and describe the creative process that forms the pedagogical base and review the theory and practice that constitute Escola Casa Verde's educational dynamic. The richness of the learning experience sometimes surpass attempts at characterization. Words can seem an insufficient measure. In summary, Escola Casa Verde transforms what could be repetitive inertia in early childhood education into a creative and sound pedagogical base bringing with it, the excitement of the unexpected.
\end{abstract}

\footnotetext{
* Pedagoga, Mestre em Educação (UCB). E-mail: mariadocarmoueg@gmail.com.br

** Letras Vernáculas (UFG) Especialista em Planejamento Escolar (UNESCO). Diretora Pedagógica da Escola Casa Verde. E-mail: maria-eliz@bol.com.br

*** João Batista de Lima. Graduação em Administração e Gestão Pública. Diretor Administrativo da Escola Casa Verde. E-mail: jpai_7@hotmail.com
} 
Keywords: Escola Casa Verde, early childhood education, sustainability, pedagogical and creativity

\section{Inicio de prosa: o fio da história}

Tudo começou na Cidade de Goiás em 1981. Ano em que a professora Elizete Maria de Lima inaugurou, numa família de oito irmãos, uma linhagem de educadores. Nesse ínterim, mudou-se para a Capital - Goiânia. Aqui atuou em instituições educacionais de renome. Ministrou inúmeros cursos de capacitação de professores nas redes pública e privada de ensino, sob a marca registrada de justo fazer e instigar. As experiências, vivenciadas dentro e fora das salas de aula, foram somadas à expertise fraterna de três irmãos de sangue no sentido literal da palavra, João Batista, Elzita Maria e Eduardo, todos de Lima. Nascidos no interior e criados na liberdade do correcorre, dos banhos de chuva, dos cuidados com os bichos do lugar, sem sujeição a TV, ao videogame, sem obrigações, apesar de ajudar aos pais na lida da roça.. A memória afetiva da infância sempre viva e pulsante em cada um, em cada uma, aliadas ao saber pedagógico de Elizete Lima deu espaço ao fazer profissional do quarteto, materializado no que passou a existir enquanto projeto de Escola diferenciada.

Assim as experiências que ainda guardavam de memória, e o olhar na reinvenção, no trabalho e no encantamento, guiados pela responsabilidade criaram o Instituto de Educação Casa Verde (Escola Casa Verde) em 2011. Instituição privada, que cuida e educa ${ }^{1}$ crianças de dois a dez anos de idade, mediante a oferta da Educação Básica nos níveis Pré-Escola e I fase do Fundamental. Situa-se em Aparecida de Goiânia ${ }^{2}$, região metropolitana da capital do estado de Goiás. A Escola, atua, à luz das diretrizes do seu Projeto Político-Pedagógico (PPP), pautado nos parâmetros curriculares pensados pelo MEC, e ampliados por valores que fomentam o desenvolvimento integral da criança. Em interação com seus pares: crianças, educadores, famílias e comunidade vivenciam neste tempo-lugar uma revolução silenciosa, que afeta os modos do agir pedagógico e encanta os amantes e crédulos em educação: ainda é possível transformar sonhos em realidade.

1 Conforme PARECER CNE/CEB No 7/2010, p. 12: "Cuidar e educar significa compreender que o direito à educação parte do princípio da formação da pessoa em sua essência humana. [...]. Educar exige cuidado; cuidar é educar, envolvendo acolher, ouvir, encorajar, apoiar, no sentido de desenvolver o aprendizado de pensar e agir, cuidar de si, do outro, da escola, da natureza, da água, do Planeta.".

2 Rua Imperatriz, s/nº, Qd. 10, Lt. 07 - Jardim Imperial - Aparecida de Goiânia (Dez minutos do Setor Bueno/Goiânia). Tel.: (62) 3549-5154/3281-7081 E-mail: contato@escolacasaverde.com.br Site: http://www.escolacasaverde.com.br Blog: http://casaverdego.blogspot.com.br/ 
Nesse contexto, criou-se a Escola Casa Verde, desenhada no entremeio de inúmeras discussões e balizada pela tríade interrogativa:

- Que contribuições possibilitar, via escola, ao processo de desenvolvimento humano e da sustentabilidade da vida no planeta?

- Que relações hão de ser mantidas entre as pessoas e entre essas com a gama dos conhecimentos produzidos e em produção?

- Que tipo de sociedade, paulatinamente, se pode construir mediada pela ação e reflexão educativas?

Inquietações filosóficas em processo, que envolvem a criatividade e a tradição, o natural e o artificial, a ciência e a poesia, o conhecimento e a vida. Fios históricos e filosóficos que se juntaram aos fios do futuro no presente, tecendo o aprender e o ensinar. Interrogações situadas nos conhecimentos, nas agruras e belezas do mundo.

\section{O Dia-a-dia: lições do vivido}

Quem transpõe o portão da Casa Verde, em geral, encanta-se com a arquitetura do lugar e a harmonia no fazer e no ir e vir das crianças. Plantas, sombras e luz por todos os lados. Carcaças de computadores, tambores de óleo, frascos descartados viraram vasos, suporte para a poesia de Manuel de Barros e de outros poetas, que transformam a poética do espaço e integram-na como ato pedagógico. O quintal, extensão da casa, complemento do corpo, desdobra-se em viveiro, jardim, pomar, parque, horta, palco, pontes, herbário, varandas, casa na árvore - lugar de brincar, de contar histórias e causos; torres e castelos - lugar onde todos viram reis, rainhas, soldados, duendes, bruxas, fadas...

O conhecimento é ofertado às crianças em sintonia com a natureza, É comum encontrá-las lambuzadas de terra e vento, pés no chão olhos curiosos a indagar a formalidade informal dos conteúdos que são convidadas a tornar vivo. Ora sentadas embaixo das árvores em carteiras, no chão ou ainda, em volta de algum canteiro dispostas a aprender e a ensinar sobre a hora mais bonita do dia, sobre o ninho dos pássaros, sobre o caminho das formigas, sobre o desabrochar das flores... Circulam pelos diferentes espaços com responsabilidade e objetivo definido. Há uma "transfusão da natureza e comunhão com ela" (BARROS, 1992, p.187) que convida a todos para uma produção criativa.

Encharcadas dessas experiências as crianças levantam inúmeras hipóteses, teo- 
rizam, checam e perguntam de novo. Aprendem a conviver com as pessoas, as plantas e os bichos sem perder de vista que ser humano é ser gregário com os seus pares e com os outros seres da natureza. Identificam-se como partícipe do mundo e corresponsável por ele. Aprendem a olhar com respeito para o Planeta, nossa casa tão carente de humanização e cuidado.

A escola se fez e se refaz a cada dia como laboratório natural para a biologia, a geografia as ciências, os cálculos, a linguagem, a história..numa imensurável gama de conteúdos para além das inter-relações pessoais e sociais possibilitadas pela arquitetura natural, ampla e preservada. Oasis onde ainda se encontra mais de 40 espécimes da vegetação nativa do bioma cerrado ${ }^{3}$, acomodadas a outras centenárias árvores exóticas. Apesar da amplitude do espaço e das poucas paredes cada atividade tem tempo, espaços e objetivos claros; seja para favorece o desenvolvimento do corpo, da inteligência, da emoção, do senso estético ou qualquer das modalidades fundamentais a educação integral.

A singularidade deste lugar possibilita a organização coerente com a proposta de experimentação curiosa, disciplinada e significativa dos conteúdos curriculares indicados pela legislação e enriquecidos pela dinâmica do sonhado e vivido. Os lugares do saber formal saltam dos corriqueiros: caderno, tabuada, calculadora, táblete, para as árvores, a areia do pátio, a "correição" de formigas, a chegada do outono, a cantoria das cigarras e do Galo Inácio, o húmus dos canteiros. Neste contexto, em sua maioria, livres das paredes, as aulas tradicionais, os materiais didáticos comuns perdem a primazia ${ }^{4}$. Os recursos naturais assumem a essência do fazer acadêmico, assim como o conhecimento.

Por essa razão, a Casa Verde foi catalogada no mapa "caindonobrasil"57 - como escola que faz a diferença ao trabalhar com soluções criativas para os desafios educacionais.

É a ecoformação em processo que, conforme Suanno (2013, p. 160) "Possui como objeto essencial, no trabalho pedagógico, a natureza, como elo entre todas as áreas de construção do conhecimento humano".

Essa casa quintal credencia a Escola Casa Verde trabalhar com a complexidade da transdisciplinaridade. O fazer pensado como um todo, continuun, de modo integrado, articulado com o quintal. É o simples extremamente complexo. "[...] a complexidade se apresenta com os traços inquietantes do emaranhado, do inextricável, da desordem, da ambiguidade, da incerteza [...] (MORIN, 2006, p. 13). É uma prática

3 Atividades no Quintal. Disponível em: Vídeo: <Escrita a céu aberto >. Acesso 09/04/2016

4 O mapa "caindonobrasil" é um espaço para reunir práticas educacionais inspiradoras e "escondidas" pelo país. Disponível em: <Mapa - caindonobrasil >. Acesso em 08/04/2016 
singela que busca nas insignificâncias do quintal assegurar com muito mais consistência a complexidade do mundo. "Aprendendo com os pássaros" - nosso lema... Aprende-se com os pássaros, em voos, cantantes e aninhados, de infinitos desnecessários "saberes passarinhos". Os passarinhos, apesar de parecerem frágeis peças decorativas, sabem muito mais longe. Orientam-se instintivamente com os ritmos da natureza para encontrar suas rotas de migração. Também porque, aprender com os pássaros é um saber sutil, mas essencial à vida. Orientação para o encontro dos próprios caminhos sabedoria que a Escola pactua ao ensinar e ao aprender.

Os saberes passarinhos, como poetiza Manuel de Barros (2009, p. 22), são “[...] mais importantes do que aviões. / Porque os passarinhos/ Vem dos inícios do mundo/ E os aviões são acessórios". Os passarinhos lembram a singeleza do lugar e a liberdade da infância, já o compromisso acadêmico a ciência do avião. Crianças são mais importantes do que avião. Entregues ao mundo, completamente livres de qualquer preconceito, em comunhão com a singeleza da Casa, libertas das grades curriculares, dos conceitos predeterminados, aprendem como os passarinhos, transpõem os padrões formais da didática, - acessórios - e não os saberes essenciais à Vida. (Albuquerque, 2015)

A proposta pedagógica que circunscreve toda essa dimensão do vivido na Casa Verde é a abordagem interdisciplinar, urdida pela poiesis, que acontece com a transversalidade do conhecimento constitutivo de diferentes áreas dos saberes. A interdisciplinaridade, entendida como abordagem teórico-metodológica, incide sobre o trabalho de integração das diferentes áreas do conhecimento, um real trabalho de cooperação e troca, aberto ao diálogo e ao planejamento (Nogueira, 2001).

Ressalte-se que a ação educativa é a pedagogia do vivo. É a educação em processo materializada no conteúdo, que se ocupa com a mediação de saberes e modos de agir. Movimento intrínseco da promoção de mudanças significativas no desenvolvimento e na aprendizagem das pessoas.

Educar tem sutilidades. "O olho vê, a lembrança revê, e a imaginação transvê. É preciso transver o mundo" (BARROS, 1976, p.75). O conteúdo se faz meio de constituição de sujeitos capazes de melhorarem sua potencialidade de escolha e de ação. Desenvolve talentos para viver, intervir na comunidade e na sociedade em consonância com o caráter de pessoa virtuosa. Caráter que, também, constitui a base de ajustamento individual à sociedade, o modo pelo qual será conhecido (ARISTÓTELES, 1992).

Nas palavras de Oliveira (2002, p.242): 
periências das de outras pessoas, pensar o presente e o passado, [...]. Suas representações sobre o tema são reelaboradas pelo olhar da professora, que, durante todo o processo, tenta apreender as hipóteses e as significações infantis.

Nessa linha de pensamento, as situações pedagógicas da Casa Verde são planejadas, deliberadas, mediadas e repensadas pelos educadores. "O sonho viável é pensar diariamente a própria prática; é a descoberta incessante de perceber e demarcar existências de espaços livres; é a liberdade da utopia” (FREIRE, 1970, p. 99). As crianças partilham os achados e as experimentações, entrelaçadas à imaginação e à realidade. Os conhecimentos e as ações se imbricam coesos com os eixos dos projetos. Fazer que coincide com o pensamento de Kramer (1993, p. 85): "As crianças são sempre diferentes umas das outras, não só em termos de seus interesses, mas também do seu ritmo de desenvolvimento e dos conhecimentos anteriormente adquiridos".

No entanto, a pedagogia ultrapassa a dimensão metódica do fazer rumo à reinvenção. (LIBÂNEO, 2003). Por isso, a Escola Casa Verde trabalha com pedagogia de projetos interdisciplinares. Processo que permeia o desenvolvimento integral da criança e o espaço para a comunidade educativa repensar suas ações.

O projeto sistematiza a organização do trabalho coletivo, otimiza o tempo, problematiza a realidade, concretiza a situação tal qual ela se apresenta para, só então, conceituar, registrar, aprender. O sentido já se mostra nos títulos: Projeto - A Arte ao Relento - Projeto que permeia todas as atividades escolares imbricando os saberes e os fazeres da arte às diretrizes curriculares e ao calendário escolar. Cada ano contempla um tema específico que costura as diferentes áreas do conhecimento: "Repetir, repetir - até ficar diferente. Repetir é um dom do estilo' (BARROS, 1993, p.23). Na culminância desse projeto acontecem as Rodas: de leitura, de cinema, de dança, de literatura, da terra, das artes e ofícios, sempre entrelaçada pelo viés da cultura. Acontecem, também, feiras culturais: fiandeiras, catireiros, dança dos tapuios, incremento da produção orgânica, consumo consciente, reaproveitamento, cooperativismo, encontro de saberes populares, artísticos, científicos, catedráticos, filosóficos, ou voluntários, independentes só para falar do amor ou celebrar a alegria do encontro. Reúnem-se pessoas de todas as áreas do conhecimento para ensinar e aprender a arte de viver mais e melhor.

A prof. Dra. Eliane Yunes ${ }^{5}$ presente no fechamento do Arte ao Relento/2011,

5 Professora Dra. Associada do Departamento de Letras da PUC/RJ. Criou para a Biblioteca Nacional, o Programa Nacional de Leitura (Proler), é assessora do Cerlalc/Unesco e assumiu a direção da Cátedra Unesco de Leitura no Brasil entre 2006 e 2013, quando passou ao Instituto Interdisciplinar de Leitura da PUC-Rio (iiLer) cujo o setor de pesquisas e publicações coordena hoje, assim como preside seu Conselho de Desenvolvimento. 
desdobrado na Roda de Leitura - "Para gostar de ler" - falou aos Professores, Pais e convidados que: "Entre as causas do desapego à leitura, a mais grave, é que a experiência deixa de ser partilhada. Os pais acham que os filhos podem ler sozinhos. Sem leitura partilhada não tem formação crítica. A leitura passa, então, a ser uma prestação de contas escolar”. A Casa Verde cria, a partir dessas estratégias pedagógicas, ambiente reflexivo, de interação criativa e honesta, mediada por profissionais qualificados que se repensam como educadores e como pessoas que abraçam o mundo na dor e na alegria do vir a ser, do devir deleuziano.

O dia-a-dia que escreve lições do vivido na Casa Verde é a própria rotina. Desde a acolhida, quando a criança chega e se despede de seus afetos. A certeza do reencontro, apruma o passo. Acomoda seus pertences: lancheira, mochila, brinquedo, agenda... e caminha pela rampa bordada de sombras da entrada até o Teatro de Arena. Travessia cotidiana. A cada passo uma conquista: a confiança, o pertencimento, a independência, a responsabilidade...

O Teatro de Arena, arquitetura natural, ladrilhado de folhas, cercado de vento e sol, coberto pela ramada de duas mangueiras gigantescas, cede lugar a varanda. As arquibancadas dos dias de festa se transformam em estantes para agasalhar o material de trabalho: jogos matemáticos da linha Montessori ${ }^{6}$, sucatas, tintas e papel convidam para a primeira atividade. Depois de guardar seus pertences, as crianças se agrupam em duas ou três para escolherem o primeiro trabalho do dia. Todas, sem distinção da idade envolvem-se nos agrupamentos em torno do que fazer, do que ensinar e do que aprender supervisionados pelas professoras, ${ }^{7}$ por ali se distraem em pensamentos e ações. Tempo de trocas cognitivas e afetivas. Camargo (2004, p.112) ressalta ao tratar das emoções na escola: "Nas relações interpessoais, a criança está internalizando significados afetivos e morais que vão constituindo sua configuração psíquica e sua identidade."

$\mathrm{Na}$ sequencia acontece um dos momentos mais importantes na Casa Verde. Trata-se da Roda de Verso e Prosa, quando as Artes incorporam os movimentos do corpo e da alma, em forma de linguagens corporais - desinibidas ou acanhadas - musicais, dramáticas, poéticas ecoam pelos quatro cantos da Casa. Tempo, também, de brincadeiras: Chicotinho Queimado, Boca de Forno, Morto-Vivo, Batata Quente, Casinha, entre tantas outras, atuam como fonte de desenvolvimento pessoal e interacional, uma vez que estabelecem conexões do antigo com o novo, da memória com

6 Montessori (1870-1952) distinguiu-se na educação, entre outros feitos, por criar de materiais específicos à exploração sensorial pelas crianças e próprios ao alcance de cada objetivo educacional.

7 Rotina inicial. Disponível em: Vídeo: < Agrupamentos>. Acesso em 09/04/2016 
a imaginação, da realidade com a fantasia A brincadeira é pedra de toque, na Casa Verde, para as crianças produzirem novos significados.

$\mathrm{Na}$ música, na dança e na dramatização as crianças transmitem uma parte de si próprias, revelam o pensamento e a visão do mundo. $\mathrm{O}$ trabalho com a dança na escola, Fux (1983, p.40) confirma: "A dança não deve ser privilégio daqueles que se dizem dotados, ela deve ser ministrada na educação comum como uma matéria de valor estético, de peso formativo, físico e espiritual". Por outro lado, é notório que as crianças têm movimentos espontâneos, às vezes descoordenados, mas dança e se expressa sem amarras no corpo. Compete à escola levá-la a adquirir consciência dos movimentos, preservando a desenvoltura e espontaneidade sem reprimi-la, para que assim desenvolva todo seu potencial corporal e criativo (CAPRI, 2008).

As artes subsidiam a educação das crianças na Casa Verde. O fazer artístico é exercício de sensibilização, capitalizam as dores e as alegrias do mundo em brechas para suportar as dificuldades e admirar o belo, ao tempo em que abre janelas para a reflexão e a transformação do cotidiano. $\mathrm{O}$ estudo e a vivência das artes oferecem às crianças uma oportunidade para um novo olhar e escuta diferenciados do mundo pulsante, às vezes, absurdo. Dinâmica que se abre em nuances para a leitura da criação artística como ferramenta de manifestação pessoal, social e cultural. Habituar a pessoa desde a infância a ser de um modo ou de outro é de suma importância, aliás é tudo (ARISTÓTELES, 1992).

As famílias, também integrantes do dia-a-dia das lições do vivido, atuam como coautoras no cotidiano da aprendizagem das crianças. Constituem uma das chaves para educar e cuidar com vistas ao pleno desenvolvimento da pessoa, conforme preceitua a Constituição Federal (artigo 205) e na LDB (artigo $2^{\circ}$ ), a educação, direito de todos, é dever da família e do Estado. A escolha das famílias pela Casa Verde, escola que quebra paradigmas, traz na esteira o diálogo. Ora são chamadas, ao que respondem de pronto, ora se antecipam para uma conversa amistosa, tonalizada por satisfações e expectativas.

Para conhecer a história de vida de cada criança, a escola promove uma entrevista, na Roda de Verso e Prosa. Convite de honra, com todo o ritual necessário: planejamento minucioso, observação, avaliação da experiência em ação e replanejamento. Cada família, a seu tempo, vem compartilhar a sua história. Trazem memórias narradas e guardadas em caixinha enfeitada, em gaveta perfumada: o primeiro cachinho do cabelo, a primeira roupinha, o primeiro sapatinho ou aquele guardado mais especial no cantinho do coração, aquecedores de alma, porque conta a história de cada um. $\mathrm{Na}$ entrevista as perguntas: Quem é você papai? Quem é você mamãe? Como foi o nasci- 
mento de seu filho? Quem escolheu o nome? Como foram as primeiras relações dele com a família, com a escola com o mundo? Indagações que abrem espaço para saber de todas as características físicas, de modos de agir e de pensar de cada um.

Narrativas singulares que só as famílias sabem contar. A história de vida, os traços particulares, a realidade familiar de cada criança, é recebida pelo com curiosidade, emoção e respeito.

Neste convívio, ensina e aprende outra linguagem: a dos afetos e das emoções. Memórias cotidianas, tradições remotas - heranças de coragem e medo, de mania e qualidade, saberes e fazeres - regidas pela afetividade, emprestam vida a - Roda de Verso e Prosa - A cada visita - alunos, professores pais, avós, tios, madrinhas... viram professores, palhaços, contadores de história, experimentam lições de respeito pelas crenças, etnias, costumes, histórico familiar, enfim pelos mais diversos jeitos de ser e de estar no mundo. Roda de tudo nesta poética de Verso e Prosa.

As histórias de vida ultrapassam o assunto do dia e se estendem semana afora numa coletânea de atividades escritas interligadas às competências previstas nos referenciais curriculares para os diferentes grupos de dois a dez anos. Ganham o nome, o retrato, a identidade de cada um. Fortalece-se, nesse fazer/saber, a identidade da criança, no que há de mais genuíno do ser de cada um e desenvolve sua autoestima. As famílias são fundamentais nesta construção. A identidade é uma construção gradativa, estabelecida nas interações sociais, quando a criança, alternadamente, imita e se funde com o outro para diferenciar-se em seguida. A autoestima que a criança, aos poucos desenvolve é, em grande parte, a interiorização da estima que se tem por ela e da confiança da qual é alvo A postura corporal, somada à linguagem gestual, verbal, escrita do adulto transmite informações particulares e significativas que vão ajudá-la a estabelecer vínculos e estruturar a imagem que ela e o grupo têm de cada uma e de si próprias nas diferentes situações sociais em que se inserem (MEC/SEB, 2012).

Mediados pelo afeto aprendem, crianças e adultos, que ninguém é igual a ninguém, e é isso que nos distingue e aproxima. O respeito aos nossos pares em suas limitações e potencialidades, fortalece a identidade de cada uma e, por conseguinte do grupo. Como afirma Queirós: "Concluo agora que, de tudo aprendido, resta certeza do afeto como a primordial metodologia" 8 .

A escola é, ainda, espaço em que se abrigam desencontros de expectativas, mas também acordos solidários, norteados por princípios e valores educativos pactuados por meio do projeto político-pedagógico concebido, segundo

8 Bartolomeu Campos Queirós. Disponível em: Vídeo: <Foram muitos os professores $>$ 
as demandas sociais e aprovado pela comunidade educativa. (MEC, p. 25. 2010)

\section{A sustentabilidade em verde práxis}

A sustentabilidade constitui a essência de um dos valores trabalhados e vividos na Casa Verde e integra a educação ambiental. Substantivada no cuidado com a preservação e na adoção da cultura do reuso, permeia várias ações desenvolvidas. Edificações, mobília, decoração... Tudo é indicativo da inter-relação discurso-prática sustentável nesta Casa.

Salas de aulas foram edificadas com materiais de demolição e paredes levantadas com adobes (tijolos de terra crua) ${ }^{9}$. Esse processo se desenvolveu por etapas. Tanto as crianças como as famílias e colaboradores se envolveram nesse fazer através de Oficinas e seminários. Escola e Comunidade reviverem experiências desse método milenar de construção saudável, de baixo custo, de baixo impacto ambiental, de grande conforto térmico, e o melhor, sem comprometer a estética da arquitetura local. $\mathrm{O}$ resultado das edificações conjugou par e passo com o ambiente, de tal forma que as salas recém-construídas dão a impressão de que sempre estiveram ali, entre as grandes e centenárias árvores. Neste cenário, quem se aventurar a transpor os portões da Casa Verde com olhar investigativo, por mais observador que seja, não conseguirá em uma única visita identificar onde e quantos ou mesmo diferenciar o que foi feito com materiais novos e o que foi realizado a partir de reaproveitamento, portanto qualquer um pode dizer, sem medo de errar, que essa prática está presente quase na totalidade.

Outra iniciativa simples e, ao mesmo tempo, de grande contribuição para consciência ambiental é o "Projeto Compostagem". Iniciado em 2012, com o apoio das Famílias. As crianças levam para casa, duas vezes por semana, um baldinho que retorna à escola com cascas de verduras e de frutas para abastecer a composteira. Desse modo, deixarão de ser um problema ambiental para tornarem-se solução e encher de vida os canteiros da Casa Verde. Prática que a criança leva para além dos muros da escola. A compostagem rende uma boa colheita: sementes, hortaliças, legumes, frutas, flores e outras plantas crescem adubadas pelo substrato preparado pelas crianças. A matéria prima para essa preparação é o "lixo" resíduos orgânicos, transformados em solo fértil, decomposição aeróbica.

A separação e destinação adequada do lixo molhado é uma atitude simples que além de render benefícios com a adubação orgânica, minimiza a proliferação de bac-

9 Sustentabilidade. Disponível em: Vídeo:<Roda de Leitura e Meio Ambiente $>$ 
térias, deixa o lixo seco mais propício para a reciclagem, oportuniza emprego, diminui a extração de recursos naturais, minimiza os aterros sanitários, aumenta a sanidade de quem lida com os materiais descartáveis, gera renda ao invés de desequilíbrio e consequentes danos à saúde das pessoas e do Planeta.

Através da Educação Ambiental podemos perceber que existem formas mais inteligentes de se lidar com o ambiente, integrando-se com ele através do desenvolvimento sustentável e que [...] a atual crise ambiental mostra apenas sintomas de uma crise mais profunda: a falta de ética e do respeito aos valores. (DIAS, 1994, p. 28)

Envolvidas pelo trabalho as crianças aprendem a aguçar o olhar para a cidade e seus descuidos. Olhos atentos, a tudo veem. Infelizmente é muito comum encontrar coisas sem serventia jogadas nas praças e ruas de nossa cidade. Quando, sob protestos, o filho convence o pai a parar o carro, criar coragem e por as mãos no lixo, quer dizer nos trambolhos encontrados pelos caminhos. E, o pai, de repente, por força justa, se vê abraçado a uma maquina abandonada, um ferro velho, uma parafernália, arriscando-se a perder a gravata ou o terno novinho. Passado o vexame, ainda no caminho, envolvido pela fruição das ideias do filho, entra na brincadeira e começam a dar formas, utilidades, ou simplesmente brincar de "desfazeres." Descartes inúteis se transformam em instrumentos musicais, mosaicos, painéis decorativos, vasos, móveis, esculturas, lustres, brinquedos, materiais didáticos e tudo mais que a imaginação permitir.

Situações concretas integradas ao cotidiano das crianças que comprovam: a Casa Verde promove a transversalidade do conhecimento.

Antes de formular um conceito, faz-se necessário vivê-lo em interrogações e ensaios de respostas. Há que se degustar, absorver a essência da pedagogia envolvente e prazerosa. Explorar os erros, os acertos e construir o conhecimento numa dialética de dentro para fora e de fora para dentro.

Mais importante que estudar o ambiente é cuidar da Casa Mãe. A prática dos atos é o que gera as atitudes virtuosas. Do que vale tirar 10 nas provas, saber de trás para diante e de diante para trás as lições estudadas, se elas não se traduzem em consumo consciente: aproveitamento integral das coisas, tratamento adequado dos resíduos, preservação das reservas, respeito ao meio ambiente, ao outro e a si mesmo? Aristóteles, apud Lorenzetti (2004, p.5) em idos milenares já registrava:

Mas a maioria dos homens não procede assim. Refugiam-se na teoria e pensam que estão sendo filósofos e se tornarão bons dessa maneira. Nisso se 
portam como enfermos que escutassem atentamente seus médicos, mas não fizessem nada do que estes lhe prescrevem.

O propósito da sustentabilidade em Verde práxis, na Casa Verde contribui para o equilíbrio da vida no planeta. Hoje, guiada pelo pacto ambiental, atua como exemplo para a posteridade.

\title{
A abertura de janelas na Legislação
}

Uma questão que parece inquietar, quando se trata de atuação diferenciada na educação escolar é a legislação. Leis e normas exigentes baseadas em padrões rígidos, mas o Art. 23 da Lei de Diretrizes e Bases da Educação (LDB) abre brechas para novas propostas, quando diz:

\begin{abstract}
A educação básica poderá organizar-se em séries anuais, períodos semestrais, ciclos, alternância regular de períodos de estudos, grupos não-seriados, com base na idade, na competência e em outros critérios, ou por forma diversa de organização, sempre que o interesse do processo de aprendizagem assim o recomendar (Grifo dos autores).
\end{abstract}

Há a presença da flexibilidade em substituição aos padrões inflexíveis e sequenciados. Importa é o processo de aprendizagem que enrijecido clama saídas: do fragmento para a integração, da individualidade para o coletivo, da objetividade para o subjetivo, da razão para a sensibilidade. Assim, a legislação permitiu a Casa Verde organizar-se em conformidade com a interação das crianças maiores com as menores e vice-versa, em grupos-seriados, nos espaços abertos e educativos do grande quintal e em outros espaços circunvizinhos. Temporalidade múltipla (DELEUZE,1992) no contraponto da temporalidade fundada em visões da história e da psicologia, que contemplam etapas e sucessões cronológicas. A organização foi, dessa forma, pensada de antemão no PPP e, por vezes, acontece sua reescrita com ideias extraídas dos pés e das asas das crianças, ainda flexíveis e leves sem o vício dos ritos escolares gradeados.

Nessa linha de pensamento, a LBB embasa legalmente a proposta da Escola que advoga e realiza a matriz curricular, distante da ação de enclausurar em grade. Propõe que o significado de matriz ${ }^{10}$ - Lugar onde alguma coisa nasce ou se gera - seja observado na organização do currículo. A gênese está no conhecimento.

10 In: Dicionário Priberam da Língua Portuguesa [em linha], 2008-2013. Disponível em: http://www.priberam.pt/dlpo/matriz. Acesso em 11-04-2016. 
Desse modo, o percurso formativo das crianças acontece aberto e contextualizado, sob a impossível, possível ação do Pensamento Complexo, extirpador do pensamento cartesiano e promotor das relações que existem entre os conhecimentos essenciais à visão significativa do todo (MORIN, 2007).

Inclui, além dos componentes curriculares centrais obrigatórios, consoante com as leis e as normas educacionais, outros estudos complementares e variáveis em forma de atividades que possibilitam percursos formativos em atendimento aos interesses, às necessidades e às características das crianças. Tudo acontece em uma ciranda viva e virtuosa em que a importância do dever se iguala no prazer das complementariedades. A Casa Verde adota a concepção e a organização do espaço curricular e físico como imbricados e que se alargam, por incluir no processo do ensinar e do aprender ambientes físicos, didático-pedagógicos e equipamentos que não se reduzem às salas de aula. O entorno da Escola existe como possibilidade curricular, por isso o PPP prevê e realiza tempos de aprendizagens em espaços de outras instituições escolares, socioculturais e esportivo-recreativo, além do próprio ambiente da natureza.

Há em toda Equipe uma disposição sem medida para reinventar e construir um currículo em que a desenvolvimento pessoal, a cooperação e a sustentabilidade constituam a finalidade da educação.

A pedagogia: significada por dois radicais gregos e sentida por olhares entrecruzados no "ato pedagógico"

A palavra pedagogia origina-se de dois radicais da língua Grega: "Paidos" (criança) e "Agogé" (condução). Essa procedência se propagou imbricada à prática educativa. Assim, Saviani argumenta: “Em sua trajetória multissecular, a característica mais saliente da pedagogia, pode ser identificada na relação teoria-prática (2007, p. 99). Durante muitos e muitos anos, prevaleceu a concepção da teoria mais importante do que a prática. Apenas no início do século XX houve o deslocamento para a importância da prática em detrimento da teoria. Mas, essa transferência de lugar ocorreu sem hegemonia. A herança cultural se manteve em disputa com o novo pensamento e o dilema se instalou: Adotar como fundamento da pedagogia a teoria ou a prática? Saviani (p. 107) instiga: "A pergunta que cabe formular é, portanto, a seguinte: existiria um outro caminho, uma outra tendência pedagógica que permitiria superar o dilema em que se encontra enredadas as tendências pedagógicas contemporâneas?"

A tentativa de responder esse questionamento está presente na trajetória da 
Casa Verde. Aqui a práxis possibilita agir e refletir e agir de novo e de novo refletir. Fluir, ir além sem oposição entre teoria e prática. Uma subsidia a outra. A mediação de saberes e modos de agir, como já descritos, gestam mudanças no desenvolvimento de humanidade nas pessoas. Para isso há o PPP, o programa de ação, indicativos da direção de sentido da docência. O único meio de que se oferece para lidar com a imprevisibilidade é planejar as ações. Ações que assumem o poder de uma promessa e realizam-se iluminadas com pelos estudos que servirão de alicerce ao planejamento e replanejamento.

Neste contexto, na Casa Verde o 'Memórias inventadas", o "Gramática expositiva do chão", livros poéticos de Manuel de Barros corrobora em igual peso de estudo com livros de Paulo Freire, Libâneo e tantos nomes de pesquisadores em educação. Tudo acontece em nome do reinventar o encantamento do fazer e o pensar educativos, situados na complexidade deste tempo, no ir-e-vir do ato pedagógico. Para isso muito contribui as premissas de Deleuze e Guattari sobre um novo jeito de olhar e de pensar as diferenças as crianças em contínuo devir.

O desafio é liberar as ações dos ranços de outras tendências pedagógicas que insistem em se fazer presentes e amarrar o exercício de aprender e de ensinar

\section{Prosa de despedida}

Ao encerrar este trabalho, algumas perguntas dimensionam a conclusão inconclusa deste texto: Será que as palavras são pequenas para captar toda a criatividade que atravessa os fazeres e os saberes desta Escola? Ou talvez seja nossa inserção neste lugar que entrava o olhar e a escuta, já acostumados com a rotina de cinco anos de uma pedagogia, que se tece poética e diferenciada? Ou ainda a dificuldade de entrelaçar teoria séria com estética?

Quem sabe, a Casa Verde possa em sua dinâmica, rodar para movimentos pedagógicos impensados. Quiçá, nessa esteira, possibilitar o fomento, o motivo, a agonia e a beleza não só nas crianças, mas em todos, atores e autores, que acreditam neste projeto, vida intensa em criatividade, rupturas com o lugar comum. Trata-se da promoção de um leque de possibilidades da escola, da troca da inércia repetidora por experiências e acontecimentos inesperados. Quem sabe instaurar, conforme, também, deseja Kohan (2004. P. 25): "[...] mundo do devir e não apenas da história, tempo de aión e não somente de chrónos”.

Assim, talvez, a métrica de Manuel de Barros se realize: "A gente descobre que o tamanho das coisas há de ser medido pela intimidade que temos com as coisas. 


\section{Referências}

ALBUQUERQUE, É. de. Manoel e Marta Barros: a pedagogia do olhar. 2015. Disponível em: <http://repositorio.ufpe.br/bitstream/handle/123456789/16429/Disserta\%C3\%A7\%C3\%A3o_ErikaBandeira_BC.pdf?sequence=1\&isAllowed $=y>$ Acesso em $10 / 04 / 2016$.

ARENDT, H. A Condição Humana. 10. ed. Rio de janeiro: Forense Universitária, 2009.

ARISTÓTELES. Ética a Nicômaco; Poética / Aristóteles; seleção de textos de José Américo Motta Pessanha. - 4. ed. (Os pensadores; v. 2) Ética a Nicômaco: tradução de Leonel Vallandro e Gerd Bornheim da versão inglesa de W.D. Ross; Poética: tradução, comentários e índices analítico e onomástico de Eudoro de Souza, São Paulo: Nova Cultural, 1991.

BARROS, M. Uma Didática da Invenção, poema de O Livro das Ignorãnças, ed. Civilização Brasileira, 1993.

Livro sobre nada. Ed. Record, 1996

O Livro das Ignorãças. 12. ed. São Paulo: Record, 2006

. Memórias inventadas - As Infâncias de Manoel de Barros, São Paulo: Planeta do Brasil, 2010.

BRASIL. Lei 9.394, de 20 de dezembro de 1996. Lei de Diretrizes e Bases da Educação Nacional. Disponível em: <http://www.planalto.gov.br/ccivil_03/leis/L9394.htm>. Acesso em 16/02/2016.

. Constituição Federal de 1988. Brasília, D.O.U, 05/10/1988.

. Diretrizes Curriculares Nacionais Gerais para a Educação Básica. Ministério da Educação. Secretaria de Educação Básica. Diretoria de Currículos e Educação Integral. Disponível em: <http://portal.mec.gov.br/index.php?option=com_docman\&view=download\&alias=15547-diretrizes-curiculares-nacionais-2013-pdf-1\&Itemid=30192>. Acesso em 06/12/2015. 
Ministério da Educação e do Desporto. Secretaria de Educação Fundamental. Referencial Curricular Nacional para a educação infantil. Vols.2 e 3. Brasília: Mec/SEF, 1998.

CAMARGO, D. As emoções e a escola. Curitiba: Travessa dos Editores, 2004.

CAPRI, F. S.; FINCK, S. C. M. A dança no contexto da educação física: uma análise da prática de ensino de professores e de acadêmicos no processo de formação docente. Atas digitais. Disponível em: <http://www.pucpr.br/eventos/educere/educere2008/ anais/pdf/566_360.pdf>. Acesso em: 15/03/2013. DELEUZE, Gilles. Conversações. São Paulo: Editora 34, 1992.

DELEUZE, G. Conversações. São Paulo: Editora 34, 1992.

DELEUZE, G., GUATTARI, F. Mil Platôs. Capitalismo e Esquizofrenia. Vol. IV. São Paulo: Editora 34, 1997.

Mil Platôs. Capitalismo e Esquizofrenia. Vol. V. São Paulo: Editora 34, $1997 \mathrm{~b}$.

DEPRESBITERIS, L. Educação Ambiental: algumas considerações sobre interdisciplinaridade e transversalidade. In: NOAL, F.O.; REIGOTA, M; BARCELOS, V.H.L. (org.) Tendências da Educação Ambiental brasileira. Santa Cruz do Sul: EDUNISC, 1998. p.127-143.

DIAS, G. F. Atividades interdisciplinares de educação ambiental. São Paulo: Global, 1994.

FREIRE, P. Pedagogia de Oprimido. 17ª ed. RJ: Paz e Terra, 1987.

FUX, M. Dança, experiência de vida. São Paulo: Summus, 1983

GUATTARI, F.; BITTENCOURT, M. C. F.; ROLNIK, S. Las tres ecologías. Campinas: Papirus, 1990.

LIBÂNEO, J. C. As teorias pedagógicas modernas revisitadas pelo debate contemporâneo na educação. In: José Carlos Libâneo e Akiko Santos (orgs). Educação na era do conhecimento em rede e transdisciplinaridade. Campinas: Alínea (2005): p. 19-63. 
Diretrizes curriculares da pedagogia: imprecisões teóricas e concepção estreita da formação profissional de educadores. Disponível em: <http://www.scielo.br/ pdf/\%0D/es/v27n96/a11v2796.pdf. Acesso em 21/05/2014.

O debate sobre o estudo científico da educação: ciência pedagógica ou ciências da educação? Revista Espaço Pedagógico, Passo Fundo, v. 10, n. 2, jul./dez. 2003.

LORENZETTI, J. P. Ética a Nicômaco - Resumo e Análise. Consciência.ORG (abril de 2004), disponível em < www.consciencia.org/aristotelesjosemar.shtml> Acesso em: 12 set. 2015.

KOHAN, Walter Omar (org.) Lugares da infância: filosofia. DP\&A, 2004.

KRAMER, S. Com a pré-escola nas mãos: uma alternativa curricular para a educação infantil. São Paulo: Ática, 1993.

MARTINS, I. T. Terra nossa casa: momentos de decisão. Porto Alegre: Ediplat, 2002.

MORIN, Edgar. Introdução ao pensamento complexo. Tradução de Eliane Lisboa. Porto Alegre: Sulina. 2007.

NOGUEIRA, Nilbo. R. Pedagogia dos Projetos: uma jornada interdisciplinar rumo ao desenvolvimento das múltiplas inteligências. São Paulo: Érica, 2001.

OLIVEIRA, Z. R. de. Educação Infantil: fundamentos e métodos. São Paulo: Cortez, 2002.

SAVIO, L. A Poética de Manoel de Barros: uma sabedoria da terra. Literatura y linguística, n. 15, p. 67-80, 2004.

SUANNO, J. H. Escola Criativa e Práticas Pedagógicas Transdisciplinares e Ecoformadoras. 2013. 297 fl. Tese de Doutorado em Educação. Universidade Católica de Brasília - UCB, Brasília, 2013.

Recebido em: 19 abril 2016

Aceito em: 29 abril 2016 